\title{
RATIONAL USE OF THE SECONDARY RESOURCES OF THE VINEYARD AND WINEBRANDING INDUSTRY
}

\author{
Lev A. Oganesyants, Alexander L. Panasyuk, Elena I. Kuzmina* \\ All-Russian Scientific Research Institute of the Brewing, Non-Alcoholic and Wine Industry - \\ Branch of the V.M. Gorbatov Federal Research Center for Food Systems of Russian Academy of Sciences, Moscow, Russia
}

KEY WORDS:

red grape leaves, phenolic

substances, resveratrol, angeoprotective properties, $\mathrm{CO}_{2}$ extraction, physiological value

\begin{abstract}
In the grape processing, secondary resources are primarily the remnants of the generative plant organs (berries) sweet and fermented husks of grapes, seeds, peels, etc. However, the use of vegetative organs - vines, which are more promising, of grape leaves is promising. It is shown, that red leaves of grape are a source of phenolic compounds, resveratrol and other antioxidants, and also contain activators of enzymes, that cause venotonic and angioprotective properties. The most valuable in this respect are red grape leaves, which grow in covering areas, because on the eve of winter, as a defense against the cold, they accumulate a greater amount of resveratrol. The use of $\mathrm{CO}_{2}$-extraction technology in the processing of red leaves makes it possible to obtain extraction cake with a high content of biologically active substances due to the destruction of the cell structure during the extraction process. At the same time, the hydrophilic extract of the extraction cake after $\mathrm{CO}_{2}$-extraction has the greatest value, it is well soluble in water and is intended to enrich the soft juice based on grape juice with biologically active substances. A technology was developed for using $\mathrm{CO}_{2}$ extracts of grape seeds to stabilize margarine emulsions against oxidation and to increase the thermal stability of frying fats.
\end{abstract}

\section{Introduction}

The use of secondary resources is one of the main tasks in ensuring the productivity of processing industries. At the same time, it is fundamental, on the one hand, to mitigate the impact on the environment, and on the other, to obtain additional new types of products. This is especially relevant in industries engaged in the processing of vegetable raw materials, since the secondary production resources are of biological origin and can be the starting material for food production.

In grape processing, secondary resources are primarily the remnants of the generative plant organs (berries) - sweet and fermented husks of grapes, seeds, peels, etc. However, it is promising the use of vegetative organs such as vines and vine leaves. [1].

The leaves of red grapes in autumn are colored red, due to the anthocyanins presence. In France, for a long time (the first references refer to the 17 th century), red vine leaves were used to treat swollen, painful feet. The peasants working in the vineyards, after the grapes were harvested, collected red leaves, insisted on grape alcohol and were used as compresses for the legs in winter, as well as consumed with a teaspoon inside. It is known, that France has the lowest incidence rate of varicose veins, which is largely facilitated by the use of red grape leaves as a medicine. Red grape leaves are officially listed in the 9th edition of the French Pharmacopoeia. The indications for their use are venous insufficiency, expressed by the symptom of «heavy legs», swelling, and the manifestation of fragility of the vessels and capillaries. [2-5]. It has been established, that the alcoholic extract of grape leaves, exhibits antioxidant activity, has a hepatoprotective and neuroprotective effect $[6,7,8]$.

The main biologically active components of the leaves are catechins, flavonoids, tannins, malic, silicic, citric, tartaric and succinic acids and resveratrol. According to the literature, grape leaves contain polyphenolic compounds: hydroxy derivatives of stilbenes - resveratrol, viniferin, astringin, piceid; flavonoids - quercetin, isoquercetin; as well as phenol carboxylic acids, tannins, anthocyanins, lipids, sugars, terpenoids, vitamins; polyamines - putrescine, cadaverine, spermidine, spermine, agmatine and other components $[9,10]$.

Resveratrol is a substance, belonging to the stilbene group. There are evidences of studying stilben-containing extract of grapevine pruning [11]. Resveratrol is phytoalexin, which is naturally produced by certain plants in response to stress, damage, fungal infection and ultraviolet radiation. It is found in the skin and stem of red grapes, raspberries, mulberries, plums, peanuts, blueberries and blueberries, red leaves of grapes, as well as in the roots and stems of the Japanese knot grass (Polygonum aviculare) $[12,13]$.

In nature, there are two forms of resveratrol: cis-resveratrol and trans-resveratrol. Trans-resveratrol is more stable form. Under the influence of ultraviolet rays, it turns into possessing a large supply of energy, and therefore less stable, cis-resveratrol. Compared with the cis form (cis-3,4-5-trihydrostilbene), transresveratrol (trans-3,4-5-trihydrostilbene) has a greater biological and antioxidant activity [14].

The main property of dietary supplements, containing resveratrol and red grape leaf extract is the ability to strengthen the walls of the thinnest capillaries, reduce their permeability, restore their resistance, ensuring their normal functioning and improving blood microcirculation. Resveratrol also normalizes heart rhythm and blood pressure. Resveratrol lowers cholesterol and triglycerides in plasma. It also prevents lipoprotein oxidation, which prevents the possibility of its deposition on the walls of blood vessels, thereby reducing cardiovascular diseases risk. Resveratrol has antibacterial and anti-inflammatory effects, stimulates natural defense mechanisms, improves blood circulation in the tissues $[1,15,16,17]$.

According to researchers, most resveratrol is found in grapes growing in cold climates. This substance helps the grapes to survive in winter. A large amount of resveratrol in trans form forms in plants in response to stressful situations.

In the conditions of our country, the use of red grape leaves is particularly effective due to special climatic conditions. First, part of the vineyards is located in the area of sheltered viticulture, and therefore, to improve wintering conditions before the shelter, as a rule, ripe leaves are purposefully cut off, which is practiced primarily in the Rostov region. Secondly, the grape plant resists shock from the cold better, producing increased amounts of resveratrol, which makes red leaves a very valuable raw material in terms of the content of biologically active substances. 


\section{Materials and Methods}

The All-Russian Scientific Research Institute of Brewing, Non-Alcoholic and Wine Industry, together with the Institute of Medicinal and Aromatic Plants of the Russian Academy of Sciences, conducted studies on the physicochemical composition and biological activity of red grape leaves. After the harvest were selected samples of red autochthonous and European grape varieties grown in the Rostov region - Krasnostop Zolotovsky, Tsimlyansky Black, Golubok, Cabernet Sauvignon, Saperavi.

Dry extracts from red grape leaves of different grape varieties were prepared under laboratory conditions at the All-Russian Research Institute of Medicinal and Aromatic Plants according to the method, described in the Pharmacopoeia of the Russian Federation OFS.1.4.1.0018.15

A comparative study of dry extracts of different red grape leaves varieties enzymatic activity, as well as antistax venotonic and chemically pure resveratrol, was carried out in accordance with the methods, described in RF patents No. 2181890. 2001, № 2181891. 2002, No. 2181892. 2002.

The study of the acute toxicity of red grape leaves variety Cabernet Sauvignon was carried out in accordance with GOST R53434-2009 «Principles of Good Laboratory Practice» and «Guidelines for the Experimental Study of New Pharmacological Substances» 2005.

\section{Results and discussion}

It has generally recognized, that most medicinal herbal preparations are safe to use. However, every year there are more and more publications about negative adverse reactions caused by taking herbal medicines for several reasons: raw materials quality, method of preparation and chemical composition of the selected BAS, the choice of doses, the method and duration of their use, etc. [18] To make sure in feedstock safety, the Scientific Center for Biomedical Technologies of the Russian Academy of Medical Sciences conducted a study of the acute toxicity of red leaves of Cabernet Sauvignon grapes. The results of the studies indicate that when administered once to the stomach of mice, the extract of red grape leaves is a low-toxic substance and be- longs to the fourth class of toxicity according to the Hodge and Sterner toxicity classification.

In selected samples of red grape leaves were determined the moisture content, the content of extractive substances, the content of phenolic compounds, the antioxidant capacity and resveratrol mass concentration. The amount of phenolic compounds were recalculated to rutin. As it known, rutin is an organic compound from the group of flavonoids, quercetin-3-rutinoside, which has a powerful angioprotective effect. The research results are summarized in Table 1.

From the obtained results it can be seen, that the moisture content of analytical samples of plant materials varies from $8.35 \%$ to $9.91 \%$. Samples of Saperavi, Golubok, and Cabernet Sauvignon are characterized by a high content of extractive substances. Red leaves of Cabernet Sauvignon variety have the highest content of phenolic compounds $-2.85 \%$. The quantitative determination of resveratrol in autochthonous and European grape varieties confirms the assumption, that under extreme cultivation conditions, there is a greater accumulation of resveratrol as a protective substance. The highest content of resveratrol is observed in autochthonous grape varieties. The maximum content of resveratrol was observed in the autochthonous variety Golubok $-170.5 \mathrm{mg} / \mathrm{kg}$.

In order to select the most promising grape varieties with respect to venotonic and antioxidant actions, had been conducted researches to study the biological activity of extracts of red grape leaves of using glutathione reductase, pyruvate kinase and catalase biotest systems. Chemically pure resveratrol and antistax venotonic drug were used as reference agents. The data are presented in Figure 1.

As a result of the research it was found, that extracts of red grape leaves of all varieties increase the speed of the above reactions. The extract of red leaves of the Cabernet Sauvignon grape variety has rather high indicators, while the area of plantings considerably exceeds the area of other varieties planting. Thus, it is advisable to use red leaves of Cabernet Sauvignon grapes as a raw material for the production of preparations with a targeted venotonic action, as well as for food products production with increased physiological value.

Comparative analysis of various varieties of red grape leaves biochemical composition

Table 1

\begin{tabular}{lccccc}
\hline \multicolumn{1}{c}{ Grape variety name } & Moisture, \% & $\begin{array}{c}\text { Extractive } \\
\text { substances, \% }\end{array}$ & $\begin{array}{c}\text { Resveratrol mass } \\
\text { concentration, } \mathbf{~ m g / k g}\end{array}$ & $\begin{array}{c}\text { AC, mmol } \\
\text { of trolox eq/dm }\end{array}$ & $\begin{array}{c}\text { Phenolic } \\
\text { substances, \% }\end{array}$ \\
\hline Cabernet Sauvignon & $8.47 \pm 0.5$ & $23.4 \pm 1.2$ & $104.2 \pm 0.8$ & $95.4 \pm 0.02$ & $2.85 \pm 0.08$ \\
\hline Krasnostop Zolotovsky & $9.91 \pm 0.5$ & $20.9 \pm 1.2$ & $164.5 \pm 0.8$ & $75.8 \pm 0.02$ & $2.15 \pm 0.08$ \\
\hline Saperavi & $8.35 \pm 0.5$ & $27.5 \pm 1.2$ & $42.5 \pm 0.8$ & $79.3 \pm 0.02$ & $2.14 \pm 0.08$ \\
\hline Tsimlyansky black & $9.24 \pm 0.5$ & $16.0 \pm 1.2$ & $156.7 \pm 0.8$ & $76.2 \pm 0.02$ & $2.15 \pm 0.08$ \\
\hline Golubok & $8.83 \pm 0.5$ & $23.6 \pm 1.2$ & $170.5 \pm 0,8$ & $82.1 \pm 0.02$ & $2.24 \pm 0.08$
\end{tabular}

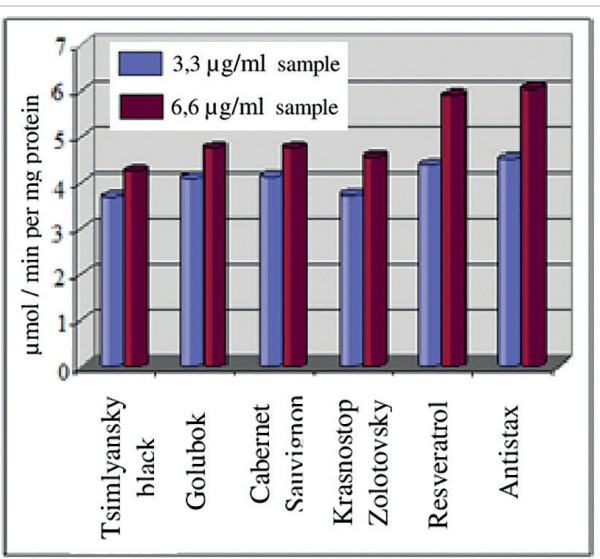

Rate of glutathione reductase reaction

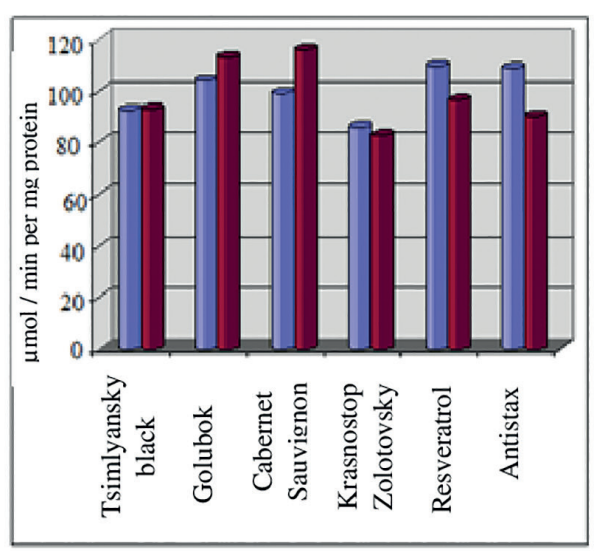

Rate of pyruvate kinase reaction

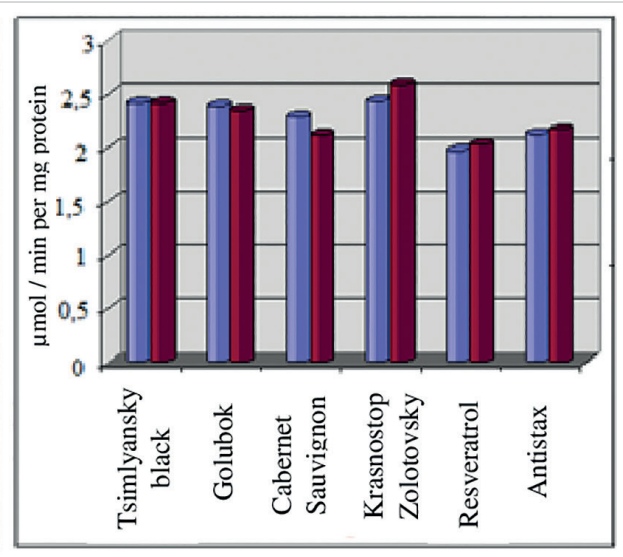

Rate of catalase reaction

Figure 1. The effect of dry extract of red grape leaves of different varieties on the rate of enzymatic reactions 


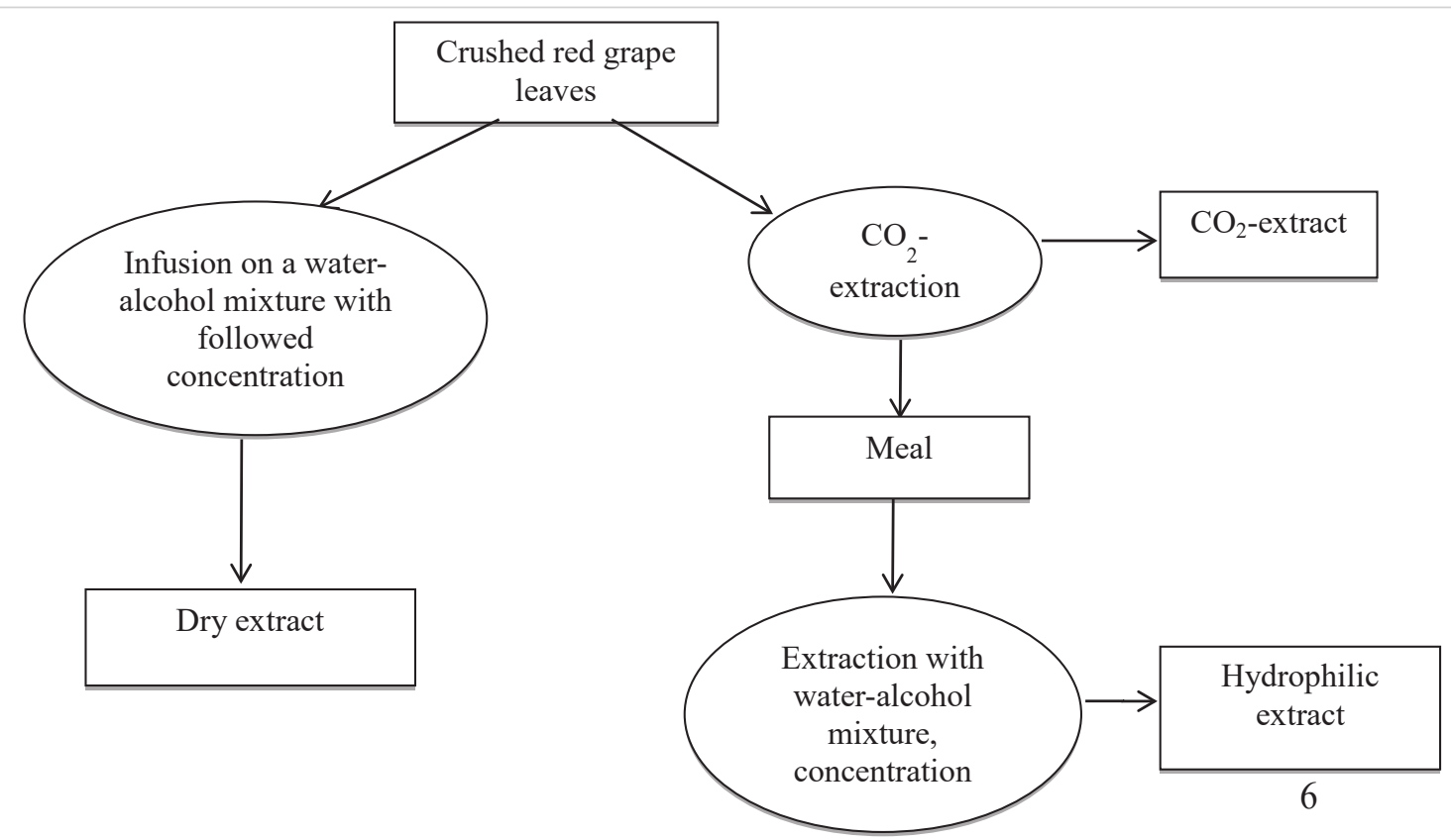

Figure 2. Scheme for obtaining extracts of different nature from red grape leaves

Red grape leaves dry extract has a high biological activity, but it is not soluble in water, which makes it impossible to use it in this form to obtain drinks with high physiological value. In order to select the optimal modes of red grape leaves extracting, extracts were prepared using various technological methods: $\mathrm{CO}_{2}$-extract, hydrophilic extract, dry extract.

The $\mathrm{CO}_{2}$-extract had been obtaining under production conditions of «Biocevtica Ltd» on the EV-130 extractor using subcritical extraction parameters - pressure of $65.5 \mathrm{~atm}$. and a temperature of $25.5^{\circ} \mathrm{C}$. Such parameters make it possible to obtain high-quality extract without negative heat exposure and at the same time to achieve the fullest yield of fat-soluble biologically active substances. In the process of extracting liquefied carbon dioxide turning into a gaseous form, breaks the membrane and organoids of the cells of the raw material, and extracts the lipophilic component. After $\mathrm{CO}_{2}$-extraction, the so-called «blasted» meal, freed from the lipid fraction, remains, with a destroyed cell structure, which contains a large amount of valuable hydrophilic compounds. This meal was used in further work to obtain a hydrophilic extract. The extraction was carried out with a wateralcohol mixture, followed by concentration. Thus, three types of extracts were obtained from red grape leaves - dry extract, hydrophilic extract $(\mathrm{HT})$ and $\mathrm{CO}_{2}$-extract. Figure 2 shows the scheme for obtaining extracts of different nature from red grape leaves.

Were carried out comparative studies of red grape leaves extracts biochemical composition, obtained by various methods. Table 2 shows the results of the researches.

As can be seen from the table, HE contains more biologically active compounds as compared with extracts, obtained by other methods. In this sample, the highest polyphenols content, in- cluding resveratrol. In addition, tocopherol (vitamin E) is present in the HE, in contrast to the dry extract. This is explained by the fact, that the gap in the walls and organoids of the cells in the process of $\mathrm{CO}_{2}$-extraction provides a more complete yield of biologically active compounds. The polyphenols, which are present in red grape leaves, have a powerful antioxidant effect, are almost completely transferred to the hydrophilic extract. They cause a high rate of antioxidant capacity (AC) in this sample.

It is known, that during $\mathrm{CO}_{2}$-extraction, the lipophilic fraction is mainly extracted from plant materials. This explains the maximum concentration of fat-soluble tocopherol in the $\mathrm{CO}_{2}$-extract. In addition, this sample has a high content of resveratrol. However, with high biological activity, the use of $\mathrm{CO}_{2}-$ extract in drinks production is difficult, as it is an oily product, insoluble in water.

In the analysis of red grape leaves dry extract biochemical composition, it was found, that the content of resveratrol and phenolic compounds in it is lower compared with other samples of extracts. At the same time, tocopherol is practically absent in the dry extract.

The results of the conducted studies allow us to conclude that the technological regimes for obtaining HE provide the greatest extraction of biologically active compounds from the raw materials compared to other methods of extraction. In addition, HE, unlike the dry extract, is highly soluble in water, which makes it the optimal biologically active additive in soft drinks production.

Because of the small amount of polyphenols, the juice of white grape varieties has a lower physiological value, but its production volumes significantly exceed the red grape juice production. In order to create an economical product with desired

\section{Comparative analysis of the red grape leaves extracts biochemical composition, obtained using various} technological methods

\begin{tabular}{|c|c|c|c|c|}
\hline \multirow[b]{2}{*}{ Sample Name } & \multicolumn{4}{|c|}{ Indicator Name } \\
\hline & $\begin{array}{l}\text { Antioxidant capacity, mmol } \\
\text { Trolox-eq/dm } \\
\text { 3 }\end{array}$ & $\begin{array}{l}\text { Mass concentration of } \\
\text { phenolic compounds, in } \\
\text { terms of gallic acid, } \mathrm{g} / \mathrm{dm}^{3}\end{array}$ & $\begin{array}{l}\text { Mass concentration of } \\
\text { resveratrol, } \mathrm{g} / \mathrm{dm}^{3}\end{array}$ & $\begin{array}{l}\text { Mass concentration of } \\
\text { tocopherol, } \mathrm{mg} / \mathrm{dm}^{3}\end{array}$ \\
\hline $\mathrm{CO}_{2}$-extract & $2.02 \pm 0.1$ & $2.01 \pm 0.1$ & $0.22 \pm 0.01$ & $45.9 \pm 2$ \\
\hline Hydrophilic extract & $13.5 \pm 0.6$ & $4.46 \pm 0.1$ & $0.44 \pm 0.01$ & $0.2 \pm 0.01$ \\
\hline Dry extract & $0.17 \pm 0.008$ & $1.11 \pm 0.1$ & $0.04 \pm 0.002$ & traces \\
\hline
\end{tabular}


Biochemical indicators of drinks, based on grape juice with the addition of red grape leaves hydrophilic extract

Table 3

\begin{tabular}{|c|c|c|c|c|}
\hline \multirow[b]{2}{*}{ Indicator Name } & \multicolumn{4}{|c|}{ Sample Name } \\
\hline & Control & $\begin{array}{c}\text { Drink with addition } \\
\text { of } 3 \% \mathrm{HE}\end{array}$ & $\begin{array}{c}\text { Drink with addition } \\
\text { of } 4 \% \mathrm{HE}\end{array}$ & $\begin{array}{c}\text { Drink with addition } \\
\text { of } 5 \% \mathrm{HE}\end{array}$ \\
\hline AC, mmol Trolox-eq/dm ${ }^{3}$ & $0.33 \pm 0.02$ & $0.66 \pm 0.02$ & $0.79 \pm 0.02$ & $0,88 \pm 0.02$ \\
\hline Mass concentration of phenolic compounds, $\mathrm{mg}$ gallic acid/dm ${ }^{3}$ & $169 \pm 2$ & $373 \pm 5$ & $442 \pm 5$ & $505 \pm 5$ \\
\hline Mass concentration of resveratrol, $\mathrm{g} / \mathrm{dm}^{3}$ & traces & $13.4 \pm 0.8$ & $17.8 \pm 0.8$ & $22.2 \pm 0.8$ \\
\hline Mass concentration of vitamin PP (nicotinic acid), $\mathrm{mg} / \mathrm{dm}^{3}$ & $1.2 \pm 0.1$ & $2.1 \pm 0.1$ & $2.4 \pm 0.1$ & $2.7 \pm 0.1$ \\
\hline Mass concentration of vitamin B6 (pyridoxine), mg/dm³ & $3.7 \pm 0.2$ & $4.6 \pm 0.2$ & $4.9 \pm 0.2$ & $5.2 \pm 0.2$ \\
\hline Mass concentration of vitamin B2 (riboflavin), $\mathrm{mg} / \mathrm{dm}^{3}$ & $1.9 \pm 0.2$ & $6.3 \pm 0.2$ & $7.7 \pm 0.2$ & $9.9 \pm 0.2$ \\
\hline Mass concentration of vitamin C (ascorbic acid), $\mathrm{mg} / \mathrm{dm}^{3}$ & $20 \pm 1.2$ & $25 \pm 1.2$ & $26,6 \pm 1.2$ & $27.9 \pm 1.2$ \\
\hline
\end{tabular}

biological properties, samples of a juice-based drink from white grape varieties were prepared with the addition of $\mathrm{HE}$ in various concentrations. HE was applied in amounts of $3 \%, 4 \%$ and $5 \%$ of the total volume. The following indicators were determined in prepared drinks: antioxidant capacity, mass concentration of phenolic compounds, mass concentration of resveratrol, mass concentration of vitamins. White grape juice without HE was used as a control. The results of the study are shown in Table 3.

As can be seen from the Table 3, the addition of HE from red leaves significantly increases the mass concentration of biologically active substances and the antioxidant capacity, and also leads to an increase in the mass concentration of all the vitamins, identified in the drink samples.

When choosing the optimal dose of HE, drinks physiological value and organoleptic characteristics were taken into account. In terms of organoleptic characteristics, the drink with a concentration of HE $4 \%$ had the most balanced taste. The developed drink is an innovative product, obtained using plant materials with high physiological value.

Grapes husks - the main secondary resources of the wine industry. Since $\mathrm{CO}_{2}$-extracts are a lipophilic fraction of raw materials, it was logical to use them in oil and fat products. The second part of our work was devoted to the study of the $\mathrm{CO}_{2}$-extracts effect on the components of grapes husks on the oil and fat products oxidative stability. The work was carrying out jointly with the Moscow branch of All-Russian Scientific Research Institute of Fats.

Today, the problem of increasing the shelf life of fat and oil products is relevant. In the vegetable oil that has been stored for a long time, there appears a rancid taste, a greasy, oliphistic taste and smell. In this regard, were conducted studies, aimed at increasing the shelf life of vegetable oils.

To obtain a $\mathrm{CO}_{2}$-extract from grape seeds at the winery of the Krasnodar Territory, were selected samples of white grapes husks (Aligote) and red varieties (Cabernet Sauvignon). From the husks of white grapes and part of the red varieties husks, the seeds were separated using a laboratory sieve. Under the production conditions of «Biocevtica Ltd» (Limited Liability Company), prototypes of $\mathrm{CO}_{2}$-extracts of separately grape seeds and separately empty husks were obtained. Extraction was carried out on an EV-130 extractor with a volume of 130 liters at a temperature of $25.5^{\circ} \mathrm{C}$ and a pressure of $65.5 \mathrm{~atm}$.

The obtained $\mathrm{CO}_{2}$-extracts were added to the oil samples in the previously optimally selected dosage, which was $0.05 \%$.

In the 1st sample, was added a $\mathrm{CO}_{2}$-extract of white grape seeds;

In the 2 nd $-\mathrm{CO}_{2}$ extract of red grape seeds;

In the $3 \mathrm{rd}-\mathrm{CO}_{2}$-extract of white grapes husks without seeds; In the 4 th $-\mathrm{CO}_{2}$-extract of red grapes husks without seeds;

As a control served oil without adding extracts.

Samples were stored for 6 months at room temperature. The original oil, before the addition of $\mathrm{CO}_{2}$-extracts, was ana- lyzing by the main indicators of oxidative damage - this is the peroxide value and the anisidine number. Organoleptic studies of oil showed the absence of extraneous smells and tastes, i.e. the oil was completely impersonal to taste, had no smell and met the requirements of GOST 1129-2013 («Sunflower oil. Technical conditions») for the refined deodorized sunflower oil. The results of physicochemical studies of oil samples - initial and after storage for 6 months are presented in Figure 3.

The results of the research indicate that the samples of sunflower oil No. 1-4 with the addition of $\mathrm{CO}_{2}$-extracts obtained from the secondary resources of the wine-growing industry, after 6 months of storage in room conditions, did not have discrediting taste characteristics and smells. At the same time, they were distinguishing by a weak herbal smell of varying degrees of intensity due to the extracts introduced into the oil. The control sample had a rich and bitter taste. When comparing the physicochemical parameters of the oil samples with $\mathrm{CO}_{2}$-extracts and the control sample, it was found that after 6 months of storage for all experimental samples, the indicators of oxidative damage - peroxide and anisidine numbers - are better than for the control sample.

No less urgent is the question of increasing the shelf life of margarine emulsions. Oxidative spoilage of margarines, like vegetable oil, is caused by the accumulation of low-molecular compounds, peroxides, aldehydes, free fatty acids, ketones, etc., in them, which leads to a sharp deterioration in the taste properties of the product. Margarines retain their quality well at low temperatures and withstand storage in conditions of positive temperatures rather poorly. In this regard, the study of the kinetics of oxidation of margarine emulsions during storage at different positive temperatures is a very urgent task.

Currently, in the production of margarine emulsions, imported hydrophilic green tea extract is used as a dietary supplement that prevents oxidation and increases shelf life. To determine the optimal supplement for margarines, $\mathrm{CO}_{2}$-extract from white grape seeds and $\mathrm{CO}_{2}$-extract of grapes husks without red grape seeds were selected as a lipophilic additive, as well as red grape leaf HE and imported hydrophilic green tea extract as a water-soluble additive. Under laboratory conditions of the Moscow branch of the Moscow branch of All-Russian Scientific Research Institute of Fats, fat-water emulsions of the «margarine» type were prepared with a fat content of 82.0.

In the fatty phase, were added $\mathrm{CO}_{2}$-extract from white grapes seeds and $\mathrm{CO}_{2}$-extract of grapes husks without red grape seeds. A hydrophilic extract of red grapes leaves and a hydrophilic extract of green tea were added to the aqueous phase of the emulsion. All additives are introduced in the amount of $0.05 \%$ by weight of the product. As a control, a margarine emulsion was prepared without extracts addition. Samples were stored at room temperature for 30 days and at $5{ }^{\circ} \mathrm{C}$ for 180 days. The research results are presented in Table 4. 

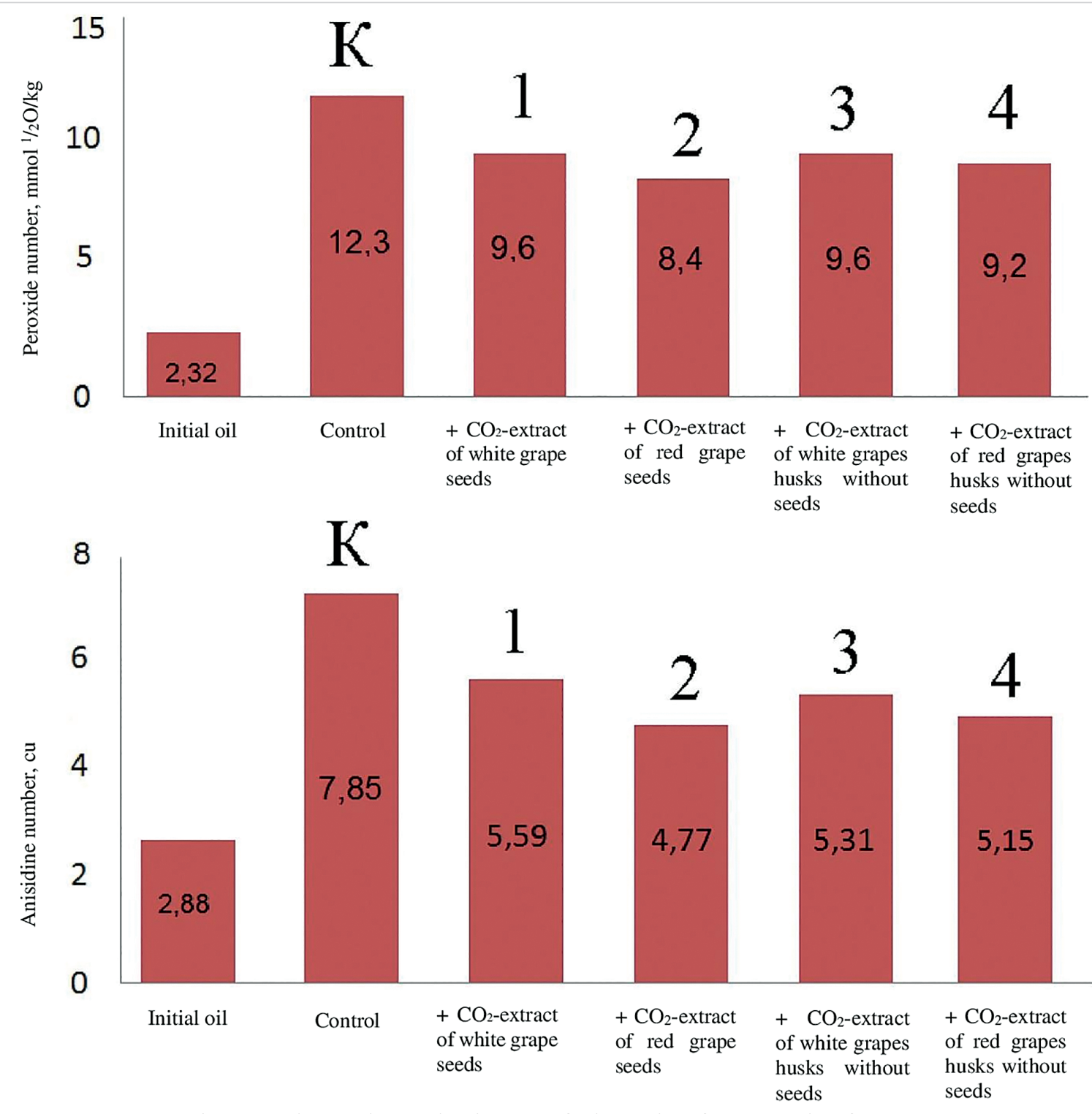

Figure 3. Physicochemical indicators of oil samples after 6 months of storage

Research of extracts of different nature effect on the margarine emulsions (ME) oxidative stability

Indicator Name

\begin{tabular}{|c|c|c|c|c|}
\hline \multirow{2}{*}{ No. } & \multirow{2}{*}{ Sample Name } & \multicolumn{3}{|c|}{ (for the fat phase, isolated from margarine) } \\
\hline & & $\begin{array}{l}\text { Acid number, } \\
\text { mg KOH/g }\end{array}$ & $\begin{array}{l}\text { Peroxide value, mmol } \\
1 / 20 / \mathrm{kg}(\mathrm{mEq} \mathrm{O} / \mathrm{kg})\end{array}$ & Anisidine number, $\mathrm{cu}$ \\
\hline $\mathrm{n} / \mathrm{n}$ & Initial ME - before putting it into storage & $0.37 \pm 0.1$ & $1.09 \pm 0.01$ & $1.15 \pm 0.2$ \\
\hline \multicolumn{5}{|c|}{30 days of storage at a temperature of $20 \pm 2{ }^{\circ} \mathrm{C}$} \\
\hline $\mathrm{C}$ & ME without extracts & $0.66 \pm 0.1$ & $8.31 \pm 0.01$ & $4.04 \pm 0.2$ \\
\hline 1 & $\mathrm{ME}+\mathrm{CO}_{2}$-extract of white grape seeds & $0.39 \pm 0.1$ & $2.37 \pm 0.01$ & $3.02 \pm 0.2$ \\
\hline 2 & $\mathrm{ME}+\mathrm{CO}_{2}$-extract of grapes husks without red grape seeds & $0.43 \pm 0.1$ & $2.63 \pm 0.01$ & $2.16 \pm 0.2$ \\
\hline 3 & $\mathrm{ME}+$ hydrophilic extract of red grape leaves & $0.40 \pm 0.1$ & $2.52 \pm 0.01$ & $2.60 \pm 0.2$ \\
\hline 4 & $\mathrm{ME}+$ hydrophilic green tea extract & $0.42 \pm 0.1$ & $2.60 \pm 0.01$ & $3.37 \pm 0.2$ \\
\hline \multicolumn{5}{|c|}{180 days of storage at a temperature of $5 \pm 1{ }^{\circ} \mathrm{C}$} \\
\hline $\mathrm{C}$ & ME without extracts & $0.71 \pm 0.1$ & $9.34 \pm 0.01$ & $2.12 \pm 0.2$ \\
\hline 1 & $\mathrm{ME}+\mathrm{CO}_{2}$-extract of white grape seeds & $0.41 \pm 0.1$ & $3.23 \pm 0.01$ & $2.04 \pm 0.2$ \\
\hline 2 & $\mathrm{ME}+\mathrm{CO}_{2}$-extract of grapes husks without red grape seeds & $0.45 \pm 0.1$ & $3.14 \pm 0.01$ & $1.62 \pm 0.2$ \\
\hline 3 & ME + hydrophilic extract of red grape leaves & $0.42 \pm 0.1$ & $4.83 \pm 0.01$ & $2.00 \pm 0.2$ \\
\hline 4 & ME + hydrophilic green tea extract & $0.42 \pm 0.1$ & $6.19 \pm 0.01$ & $1.84 \pm 0.2$ \\
\hline
\end{tabular}


Changes dynamics in vegetable oil oxidative damage indicators during high-temperature thermostating

Table 5

\begin{tabular}{|c|c|c|c|c|c|c|c|c|c|c|}
\hline \multirow{2}{*}{ Indicator Name } & \multirow{2}{*}{$\underset{\text { Original }}{\text { Oil }}$} & \multicolumn{3}{|c|}{ Control Oil } & \multicolumn{3}{|c|}{$\begin{array}{c}\mathrm{Oil}+\mathrm{CO}_{2}-\text { extract of sea } \\
\text { buckthorn seed } 0.05 \%\end{array}$} & \multicolumn{3}{|c|}{$\begin{array}{c}\mathrm{Oil}+\mathrm{CO}_{2}-\text { extract of grape } \\
\text { seed } 0.05 \%\end{array}$} \\
\hline & & 3 & 6 & 9 & 3 & 6 & 9 & 3 & 6 & 9 \\
\hline Acid number, mg KOH/g & 0.09 & 0.10 & 0.12 & 0.13 & 0.10 & 0.11 & 0.11 & 0.10 & 0.11 & 0.12 \\
\hline Peroxide value, $\mathrm{mmol} 1 / 2 \mathrm{O} / \mathrm{kg}$ & 2.8 & 13.6 & 4.0 & 3.4 & 13.8 & 3.6 & 3.3 & 13.4 & 3.7 & 2.85 \\
\hline Anisidine number, cu & 1.6 & 41.5 & 58.2 & 79.4 & 39.1 & 52.0 & 73.2 & 37.2 & 50.0 & 70.2 \\
\hline Extinction coefficient, cu & 4.2 & 6.3 & 8.3 & 11.3 & 5.8 & 6.8 & 9.35 & 5.2 & 6.4 & 8.8 \\
\hline
\end{tabular}

The results of the studies showed that margarine emulsions with the addition of $\mathrm{CO}_{2}$-extracts of white grape seeds and husks without red grapes seeds have better resistance to oxidative processes during storage at different positive temperatures compared to the model emulsion - control. Hydrolytic processes in samples with the introduction of extracts also proceed more slowly than in the control sample of margarine.

HE from red grape leaves has a positive effect on hydrolytic processes, restraining the latter at the level of the hydrophilic green tea extract used in the margarine industry, as a result of which the acid value of the fatty phase isolated from the sample of margarine No. 3 is, on average, 1.5 times lower than for control sample No. 5 (the calculation was made as an arithmetic average for 2 storage temperatures). For the hydrophilic extract from red grape leaves, a lower peroxide value of the fatty phase of margarine is characteristic compared with control No. 5, regardless of temperature and storage time. Anisidine number of sample No. 3 was lower than control No. 5 , and when stored for 30 days at a temperature of $20 \pm 2{ }^{\circ} \mathrm{C}, 1.3$ less than the sample No. 4 with green tea extract.

The organoleptic characteristics of margarine emulsions No. 1-4 at the end of the entire storage period at the studied temperatures did not have discrediting tastes and smells, remained practically impersonal, with the exception of sample No. 3, which had a slight taste due to the extract. The control sample No. 5, which was stored in the same conditions, was characterizing by a mellow flavor and a weak bitter aftertaste, which indicates the occurrence of hydrolytic and oxidative damage.

In general, it can be concluded that researched $\mathrm{CO}_{2}$-extracts can serve as an alternative to the imported hydrophilic green tea extract currently used in the margarine industry.

Fats and oils are widely used for roasting various foods. When frying products for a long time in the same deep fat, there is a significant change in the oxidative stability of oils, which has a negative impact on the products quality and safety. Studies have been conducted to determine the possibility of using $\mathrm{CO}_{2}$ extracts as substances that enhance the vegetable oils oxidative stability that are exposed to many hours of high-temperature exposure. Refined deodorized sunflower oil with previously added $\mathrm{CO}_{2}$-extracts from various raw materials was subjected to thermostatic control at a temperature of $180-185^{\circ} \mathrm{C}$ for 9 hours. The control sample was an oil without added extracts. Sampling

frequency - every 3 hours. Indicators of oils oxidative deterioration - acid, peroxide and anisidine numbers were determined. In addition, to assess the oils oxidative stability, an additional indicator was used - the extinction coefficient, characterizing the accumulation of diene compounds in oils. The research results are summarized in Table 5 .

As can be seen from the results of studies, in oil samples with the introduction of $\mathrm{CO}_{2}$-extracts, the indicators of oxidative damage are better compared with the control sample. At the same time, the acid number of all oil samples in the process of thermostating increased very little, i.e. the breakdown of triglycerides was minimal. The best results were obtained for a sample with a CO2-extract of sea buckthorn seeds, however, it should be noted that the cost of sea buckthorn seeds is much higher than the cost of grape seeds.

The increase in the indicators characterizing the secondary oxidation products is stable in the process of the entire temperature control. The increase in the peroxide value occurs during the first 3 hours of temperature control, after which the active destruction of the unstable primary occurs and the accumulation of secondary oxidation products begins to rapidly increasing the anisidine number. At the same time, the anisidine numbers in oil with the addition of $\mathrm{CO}_{2}$-extracts increase more slowly, than in the control sample. An increase in the intensity of the absorption band at a wavelength of $232 \mathrm{~nm}$ indicates an increase in the content of conjugated diene chromophores and correlates with indicators of fat thermal oxidation degree. The magnitude of the extinction coefficient for samples with the introduction of $\mathrm{CO}_{2}-$ extracts is lower than in the control sample. In general, there is a clear tendency to increase the oxidative stability of sunflower oil samples with the introduction of $\mathrm{CO}_{2}$-extracts when exposed to high temperatures for a long time.

\section{Conclusion}

Summarizing the research results, we can conclude that the obtained food additives are innovative products, which include valuable plant raw materials. In addition, when they are received, used production wastes, that are related to the secondary resources of the viticulture and wine industry, which is very important now. The introduction of red grape leaves and grapes husks extracts production will expand the range of manufactured food products with high antioxidant properties.

\section{REFERENCES}

1. Oganesyants, L.A., Panasyuk, A.L., Kuzmina, E.I., Sviridov, D.A., Sokolskaya T. A., Dargaeva T. D., Dool V. N. (2012). Prospects for the Use of Red Vine Leaves as a Secondary Raw Materials. Viticulture and Winemaking, 5, 24-26. (in Russian)

2. Eo, S.H., Cho, H., Kim, S.J. (2013) Resveratrol Inhibits Nitric Oxide-Induced Apoptosis via the NF-Kappa B Pathway in Rabbit Articular Chondrocytes. Biomolecules and Therapeutics, 21(5)5, 364-370.

3. Panasyuk, A.L., Sviridov, D.A. (2012). The main components of red grape leaves chemical composition as secondary raw material. Scientific works of the 6th Conference of Young Scientists and Specialists of the Institutes of Storage and Processing of Agricultural Products, Vidnoye, 286. (in Russian)

4. Panasyuk, A.L., Kuzmina, E.I., Sviridov, D.A. (2013). The study of red grape leaves extract as a native food additive in soft drinks production. All-Russian Scientific and Practical Conference «Food Ingredients and Innovative Technologies in the Production of Healthy Food Products», St. Petersburg, 159-162. (in Russian)

5. Panasyuk, A.L., Sviridov, D.A. (2015). The use of red grape leaves extracts as a native additive in drinks production. IX International Conference of 
Young Scientists and Specialists "Improving the Quality, Safety and Competitiveness of the Agro-Industrial Complex Products in Modern Conditions», Moscow, 292-296. (in Russian)

6. Kosar, M., Küpeli, E., Malyer H., Uylaşer, V., Türkben, C., Başer, K.H.C., (2007). Effect of brining on biological activity of leaves of Vitis vinifera L. (Cv. Sultani Cekirdeksiz) from Turkey. Journal of Agricultural And Food Chemistry, 55(11), 4596-4603. DOI: 10.1021/jf070130s

7. Orhan, D.D., Orhan, N., Ergun, E., Ergun, F. (2007). Hepatoprotective effect of Vitis vinifera L. leaves on carbon tetrachloride-induced acute liver damage in rats. Journal of Ethnopharmacology, 112(1), 145-151. DOI: 10.1016/j.jep.2007.02.013

8. Orhan, N., Aslan, M., Orhan, D.D., Ergun, F., Yeşilada, E. (2006). In-vivo assessment of antidiabetic and antioxidant activities of grapevine leaves (Vitis vinifera) in diabetic rats. Journal of Ethnopharmacology, 108(2), 280-286. DOI: 10.1016/j.jep.2006.05.010

9. Maznev, N.I. Medicinal plants: Book of reference (1999). Moscow, 167169. (in Russian)

10. Kotzabasis, K., Christakis-Hampsas, M.D., Roubelakis-Angelakis, K.A. (1993). A narrow-bore HPLC method for the identification and quantitation of free, conjugated, and bound polyamines. Analytical Biochemistry, 214(2), 484-489. DOI: 10.1006/abio.1993.1526

11. Bezhuaishvili, M.G., Meskhi, M.Yu., Bostoganashvili, M.V., Malaniya, M.L. (2005). Antioxidant activity of stilbene-containing extract in in vitro experiments. Winemaking and Viticulture, 3, 26-27. (in Russian)
12. Cho, Y. - J., Hong, J. - Y., Chun, H. S., Lee, S. K., Min, H. - Y. (2006). Ultrasonication-assisted extraction of resveratrol from grapes. Journal of Food Engineering, 77(3), 725-730. DOI: 10.1016/j.jfoodeng.2005.06.076

13. Roberts, J. S., Kidd, D. R., Padilla-Zakour, O. (2008). Drying kinetics of grape seeds. Journal of Food Engineering, 89(4), 460-465. DOI: 10.1016/j. jfoodeng.2008.05.030

14. Development of scientific bases and production methods for greening the industries of the processing and food industry in order to reduce the anthropogenic impact on the environment. Research report. (2010). All-Russian Scientific Research Institute of Brewing, Non-Alcoholic and Wine Industry of RAAS, Moscow, 29. (in Russian)

15. Khachvankyan, G.Yu, Martirosyan S.S., Avakyan, A.P., Gabelyan, E.S. (2010). Determination of cis- and trans-resveratrol by HPLC with a diode matrix in Armenian grapes, wines and winemaking wastes. All-Russian Conference "Analytical Chromatography and Kapellar Electrophoresis», Krasnodar, 271-272. (in Russian)

16. Baur, J.A., Pearson, K.J., Price, N.L. Resveratrol improves health and survival of mice on a high-calorie diet. Nature, 337.

17. Oganesyants, L.A., Panasyuk, A.L., Kuzmina, E.I., Sviridov, D.A., Trubnikov, A.N. (2013). Red grape leaves extracts - a natural source of biologically active compounds. Food Industry, 3, 40-42. (in Russian)

18. Verstakova, O.L. (2003). Preclinical examination of natural origin medicines. VII International FITOFARM Congress, St. Petersburg, 596-600. (in Russian)

\section{AUTHOR INFORMATION}

Lev A. Oganesyants - academician of RAS, doctor of technical sciences, professor, Director, All-Russian Scientific Research Institute of Brewing, Beverage and Wine Industry - Branch of V.M. Gorbatov Federal Research Center for Food Systems of RAS, 119021, Moscow, Rossolimo str., 7

Tel.: +7-499-246-67-69, E-mail: vniipbivp@fncps.ru

Alexander L. Panasyuk - doctor of technical sciences, professor, All-Russian Scientific Research Institute of Brewing, Beverage and Wine Industry - Branch of V.M. Gorbatov Federal Research Center for Food Systems of RAS, 119021, Moscow, Rossolimo str., 7, Tel.: +7-499-246-76-38

E-mail: alpanasyuk@mail.ru

Elena I. Kuzmina - candidate of technical sciences, head of the laboratory of technology of grape and fruit wines, All-Russian Scientific Research Institute of Brewing, Beverage and Wine Industry - Branch of V.M. Gorbatov Federal Research Center for Food Systems of RAS, 119021, Moscow, Rossolimo str., 7, Tel.: +7-499-246-62-75, E-mail: labvin@yandex.ru

*corresponding author

Authors are equally relevant to the writing of the manuscript, and equally responsible for plagiarism

The authors declare no conflict of interest

Received 06.05.2019 Accepted in revised 18.06.2019 Accepted for publication 25.06.2019 